\title{
Echinochrome A Protects against Ultraviolet B-induced Photoaging by Lowering Collagen Degradation and Inflammatory Cell Infiltration in Hairless Mice
}

\author{
Jung Eun Seol 1,2,3,*, Sang Woo Ahn 1미 Bomin Seol 1,2,3, Hyeong Rok Yun ${ }^{2,3}$, Nammi Park ${ }^{2,3}$, \\ Hyoung Kyu Kim ${ }^{2,3}{ }^{\oplus}$, Elena A. Vasileva ${ }^{4}\left(\mathbb{D}\right.$, Natalia P. Mishchenko ${ }^{4}{ }^{\oplus}$, Sergey A. Fedoreyev ${ }^{4}(\mathbb{D}$, \\ Valentin A. Stonik ${ }^{4}$ and Jin Han $2,3, *$ (D)
}

Citation: Seol, J.E.; Ahn, S.W.; Seol, B.; Yun, H.R.; Park, N.; Kim, H.K.; Vasileva, E.A.; Mishchenko, N.P.; Fedoreyev, S.A.; Stonik, V.A.; et al. Echinochrome A Protects against Ultraviolet B-induced Photoaging by Lowering Collagen Degradation and Inflammatory Cell Infiltration in Hairless Mice. Mar. Drugs 2021, 19, 550. https://doi.org/10.3390/ md19100550

Academic Editor: Claudiu T. Supuran

Received: 28 August 2021

Accepted: 26 September 2021

Published: 28 September 2021

Publisher's Note: MDPI stays neutral with regard to jurisdictional claims in published maps and institutional affiliations.

Copyright: (C) 2021 by the authors Licensee MDPI, Basel, Switzerland. This article is an open access article distributed under the terms and conditions of the Creative Commons Attribution (CC BY) license (https:/ / creativecommons.org/licenses/by/ $4.0 /)$.
1 Department of Dermatology, Inje University Busan Paik Hospital, College of Medicine, Inje University, Busan 47392, Korea; derma09@hanmail.net (S.W.A.); illillil@naver.com (B.S.)

2 Department of Physiology, College of Medicine, Cardiovascular and Metabolic Disease Center, Smart Marine Therapeutic Center, Busan 47392, Korea; foryou018@naver.com (H.R.Y.); nammi780314@gmail.com (N.P.); estrus74@gmail.com (H.K.K.)

3 Department of Health Sciences and Technology, Graduate School, Inje University, Busan 47392, Korea

4 G.B. Elyakov Pacific Institute of Bioorganic Chemistry, Far-Eastern Branch of the Russian Academy of Science, 690022 Vladivostok, Russia; vasilieva_el_an@mail.ru (E.A.V.); mischenkonp@mail.ru (N.P.M.); fedoreev-s@mail.ru (S.A.F.); stonik@piboc.dvo.ru (V.A.S.)

* Correspondence: injeseolje@hanmail.net (J.E.S.); phyhanj@inje.ac.kr (J.H.); Tel.: +82-51-890-6135 (J.E.S.); +82-51-890-6727 (J.H.); Fax: +82-51-897-6391 (J.E.S.); +82-51-894-5714 (J.H.)

\begin{abstract}
Echinochrome A (Ech A, 7-ethyl-2,3,5,6,8-pentahydroxy-1,4-naphthoquinone) has been known to exhibit anti-oxidative and anti-inflammatory effects. However, no study has been carried out on the efficacy of Ech A against skin photoaging; this process is largely mediated by oxidative stress. Six-week-old male SKH-1 hairless mice $(n=36)$ were divided into five groups. Except for a group that were not treated $(n=4)$, all mice underwent ultraviolet-B (UVB) exposure for 8 weeks while applying phosphate-buffered saline or Ech A through intraperitoneal injection. UVB impaired skin barrier function, showing increased transepidermal water loss and decreased stratum corneum hydration. UVB induced dermal collagen degeneration and mast cell infiltration. Ech A injection was found to significantly lower transepidermal water loss while attenuating tissue inflammatory changes and collagen degeneration compared to the control. Furthermore, Ech A was found to decrease the relative expression of matrix metalloproteinase, tryptase, and chymase. Taken together, these results suggest that Ech A protects against UVB-induced photoaging in both functional and histologic aspects, causing a lowering of collagen degradation and inflammatory cell infiltration.
\end{abstract}

Keywords: echinochrome A; photoaging; hairless mice; dermal collagen degeneration; mast cell infiltration

\section{Introduction}

Echinochrome A (Ech A) is a quinoid pigment (Figure 1A) in the polyhydroxynaphthaquinone family that is extracted from sea urchin shells or spines [1]. The moiety of Ech $\mathrm{A}$ is known to have anti-oxidative and anti-inflammatory effects [2]. In Russia, Echi A has been used as an ingredient in medication called Histochrome ${ }^{\circledR}$, showing protective effects against oxidative stress in cardiovascular or ocular degenerative disorders [3-5]. In other studies, Ech A has been shown to reduce the level of mitochondrial reactive oxygen species (ROS) in cardiomyocytes [6], exert anti-ulcerogenic effects in a gastric ulcer model [7], attenuate oxidative stress and pro-inflammatory cytokine secretion in an acute uveitis model [8], and correct imbalances in the intestinal immune system in an inflammatory bowel disease model [9]. Furthermore, several clinical trials have supported the efficacy of Ech A in various diseases such as ophthalmic, cardiovascular, cerebrovascular, inflamma- 
tory, metabolic, and malignant diseases [10]. However, so far there has been no study of the relationship between the anti-oxidative effect of Ech A and skin aging.

Skin aging is caused by a combination of intrinsic factors, such as genetic factors and hormonal changes, and extrinsic factors, including ultraviolet (UV) radiation, cigarette smoking, and mechanical stress [11]. Along with chronological aging, solar UV irradiation has been noted as a crucial component of skin aging [12]. Skin exposed to UV produces a large amount of ROS, which react with deoxyribonucleic acid (DNA), proteins, and fatty acids, resulting in oxidative damage. Oxidative stress initiates a signaling pathway cascade, which leads to the induction of activator protein 1 (AP-1) and the down-regulation of transforming growth factor beta (TGF- $\beta$ ), followed by the expression of metalloproteinase (MMP) and the inhibition of collagen synthesis $[11,13,14]$. The accumulation of metabolic disruption is manifested as morphological features of photoaged skin, such as deep wrinkles, sagging, laxity, and uneven pigmentation [12,15].

Many studies have been conducted on natural extracts in order to investigate the candidates for anti-aging products based on the anti-oxidative properties of chemicals including flavonoids, polyphenols, carotenoids, and vitamins C and E [13,14,16,17]. Plant extracts such as soy bean [18], sea buckthorn [19], turmeric, green tea, grape, soybean, milk thistle, pomegranate [20], Equisetum arvens [21], Gastrodia elata [22], Nymphaea tetragona [23], Euterpe oleracea, Matricaria chamomilla, and Camellia sinensi [24] have been widely studied. Although topical and oral applications of these plant extracts have been researched, there have been few studies dealing with skin aging and the anti-oxidative effects of marine bioactive compounds [25-29].

In this study, we investigated the in vivo therapeutic potential of Ech A against UVBinduced photoaging in a murine model. The effects of Ech A in terms of the aspects of gross visual skin condition, skin barrier function, and histologic analysis were evaluated.<smiles>CCc1c(O)c(O)c2c(c1O)C(=O)C(O)=C(O)C2=O</smiles>

D

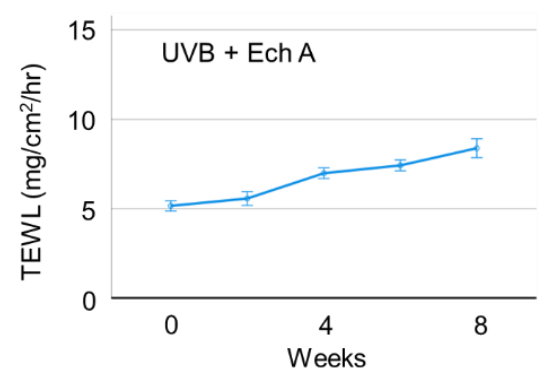

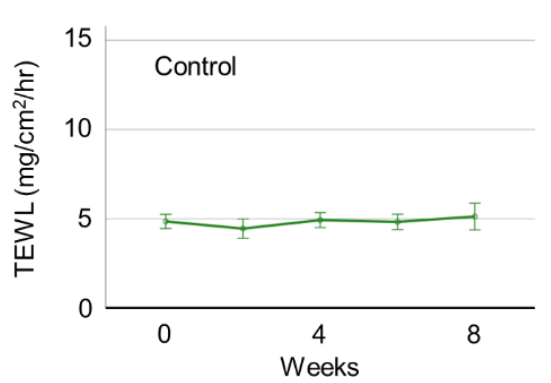

$E$

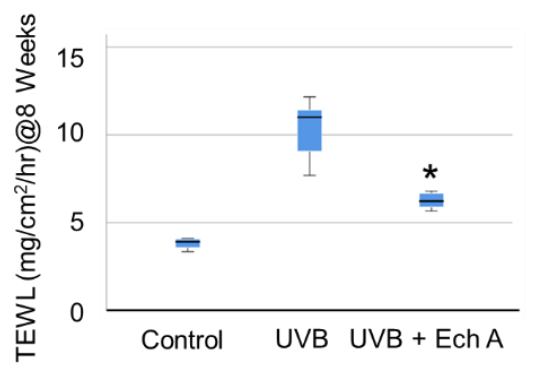

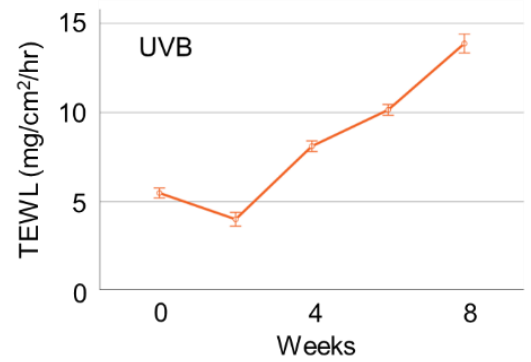

$\mathrm{F}$

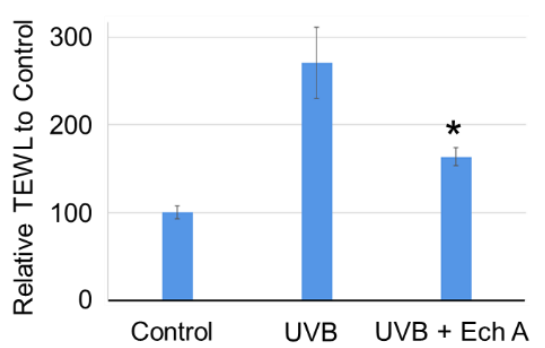

Figure 1. Changes in skin physiological function over time in the dorsal skin of UV-irradiated mice and age-matched non-treated mice. (A) The chemical structure of Ech A; (B-F) Histogram showing the transition of TEWL among the control (B), UVB (C), and UVB + Ech A (D) groups over 2 months of the experiment. Ech A injection induced a significantly low level of TEWL compared to the UVB group (E-F). ${ }^{*}, p<0.05$ vs. UVB. 


\section{Results}

\subsection{Effects of Ech A on the Skin Physiological Function}

The values of transepidermal water loss (TEWL) and stratum corneum hydration $(\mathrm{SCH})$ were measured every two weeks in the dorsal skin of mice. There was no significant difference in TEWL and SCH in week 2 between any of the groups. However, a significant elevation of TEWL and a decrease in SCH were observed in UVB-irradiated mice from week 4 (Figure 1B-D). The UVB irradiation only group (UVB) showed a more rapid elevation of TEWL compared to the UVB irradiation + Ech A-treated group (UVB + Ech A) until the end of the experiment $(p<0.05)$ (Figure 1C,D). At the end of the experiment at week 8 , TEWL was significantly higher in the UVB group compared to the UVB + Ech A group (Figure 1E,F).

Similarly, from week 4, a significant decrease in $\mathrm{SCH}$ was observed in UVB-irradiated mice (Figure 2A-C). However, there was no significant difference between the UVB and $\mathrm{UVB}+$ Ech A groups in terms of the $\mathrm{SCH}$ value at the end of the experiment (Figure 2D).

A

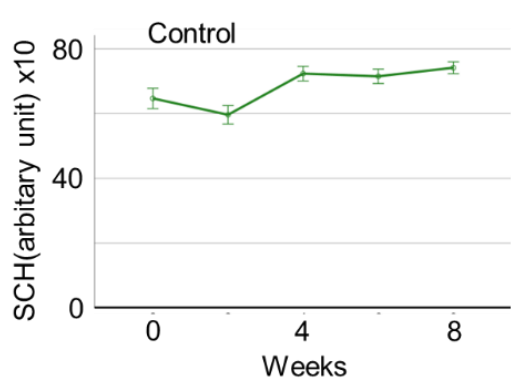

C

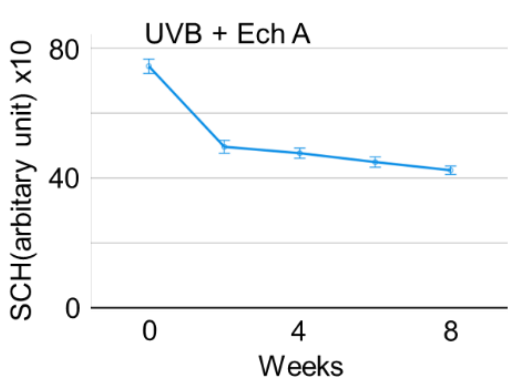

B

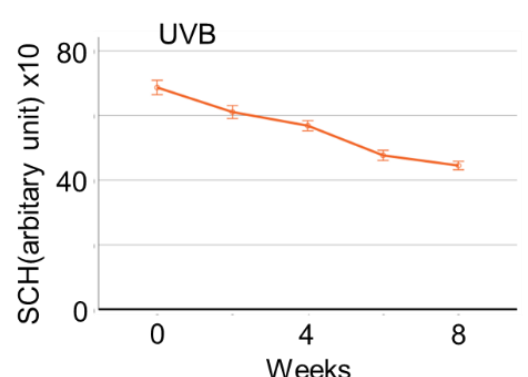

D

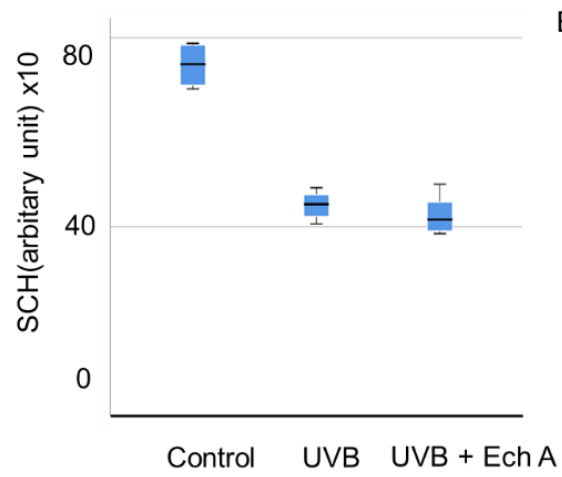

$\mathrm{E}$

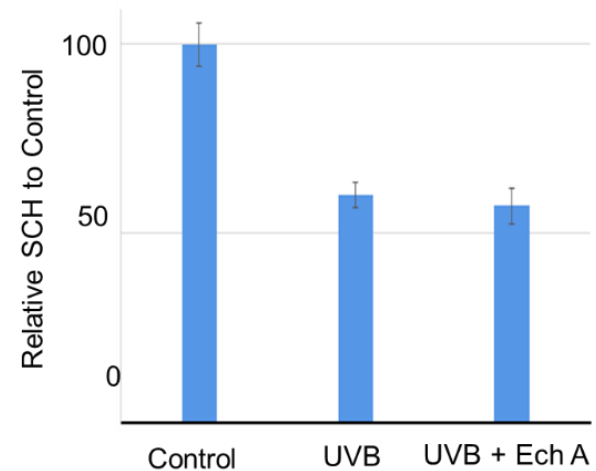

Figure 2. Changes in skin physiological function over time in the dorsal skin of UV-irradiated mice and age-matched non-treated mice. (A-E) Histogram showing the transition of SCH among the control (A), UVB (B), and UVB + Ech A (C) groups over 2 months of the experiment. There was no significant protective effect of Ech A on SCH compared to the UVB group (D,E).

\subsection{Effects of Ech A on the Macroscopic Appearance of the Mouse Skin}

On the day after the completion of the experiment, mice were observed and photographed using a camera and dermoscopy. Upon gross inspection, it could be seen that the dorsal skin of the UV-irradiated groups featured more fine superficial wrinkles, hypopigmented macules, or yellowish discoloration compared to the control group. Similar features were observed under dermoscopic inspection, showing more pronounced crossing wrinkles, irregular pigmentation with hypopigmentation and yellowish dots, and fine telangiectasia. However, there was no significant difference in gross cutaneous findings between the UVB and UVB + Ech A groups (Figure 3).

\subsection{Effects of Ech A on the Histopathologic Features of the Mouse Skin}

Upon histopathologic examination of the dorsal skin tissue, it could be seen that the UVB group exhibited prominent changes in both the epidermis and dermis. In the 
epidermis, the UVB group showed more severe hyperkeratosis, acanthosis, spongiosis, and papillomatosis than the UVB + Ech A group (Figure 4A,B).

In particular, the mean epidermal thickness (Figure 4C), papillomatosis width (Figure 4D) and papillomatosis depth (Figure 4E) were significantly increased in the UVB group compared to the UVB + Ech A group, measured as the mean value of five randomly selected areas of each H\&E tissue slide.

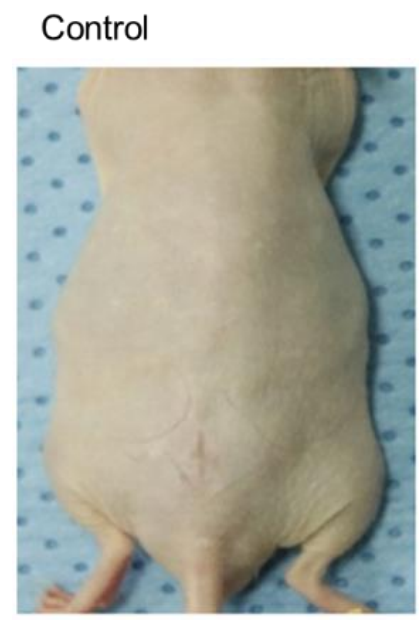

\section{UVB}
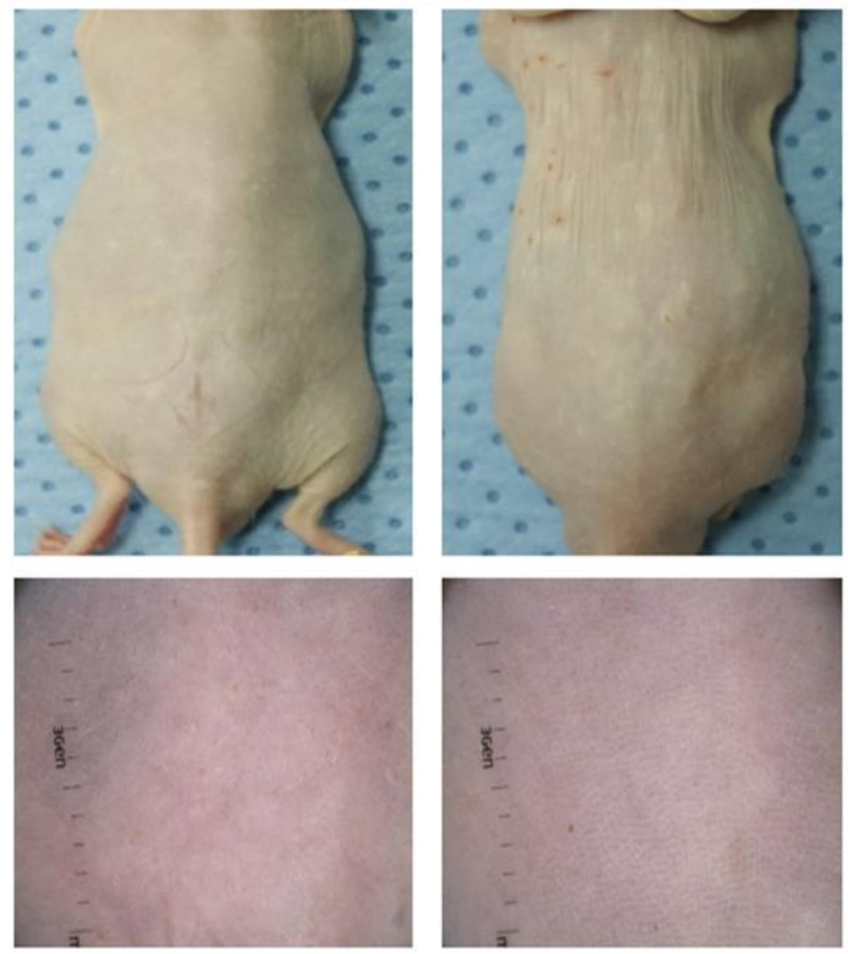

$U V B+E c h A$
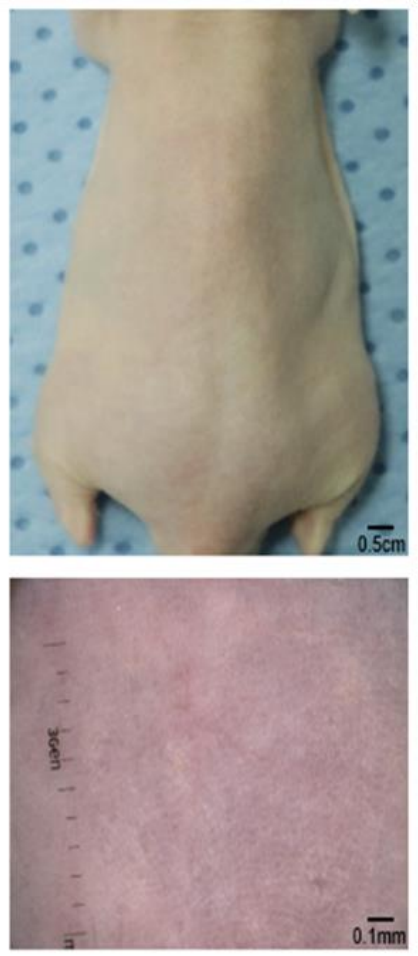

Figure 3. Macroscopic observation in the dorsal skin of UV-irradiated mice and age-matched nontreated mice. UV irradiation induced cutaneous changes, including superficial wrinkles, irregular pigmentation, and telangiectasia. There was no significant macroscopic difference between the UVB and UVB + Ech A groups.

A

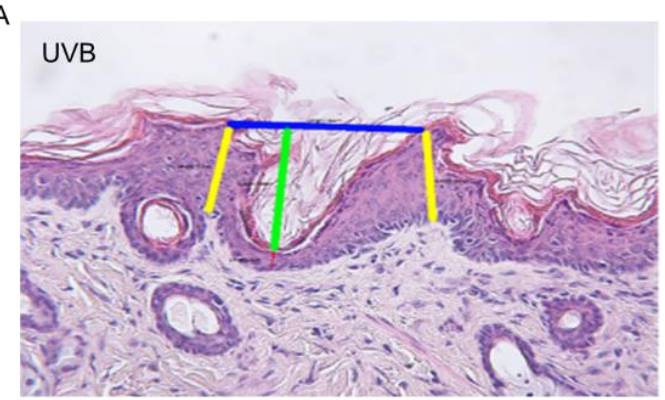

C

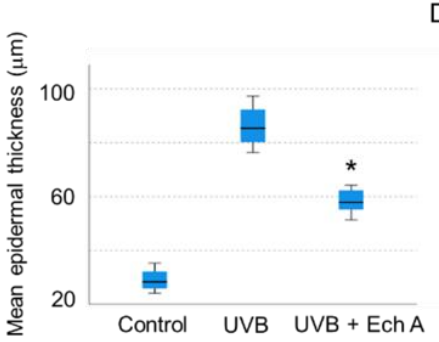

B

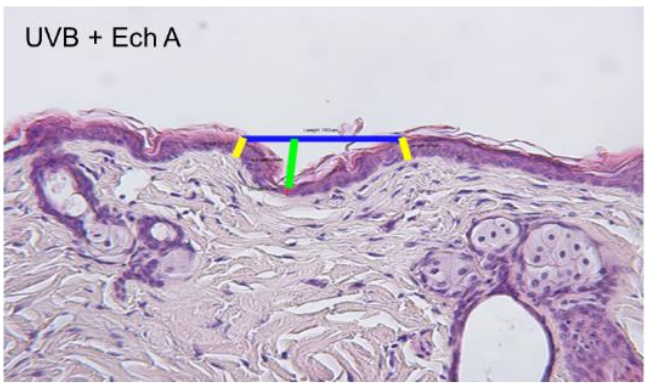

E

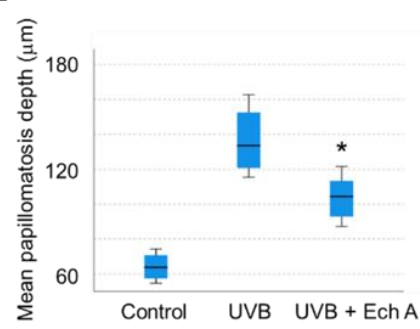

Figure 4. Histometry and statistical analysis of epidermal thickness and papillomatosis width and depth in the dorsal skin of mice. (A,B) The histometry of the site is as mentioned in the description of the method. The epidermal thickness (yellow line) and papillomatosis width (blue line) and depth (green line) of a mouse were calculated as mean values from five different sites on the H\&E slides of each mouse $(H \& E, \times 200)$. (C-E) The mean epidermal thickness and papillomatosis width and depth were all significantly higher in the UVB group than in the control group. There was significant decrease in 
In the dermis, the UV irradiation induced perivascular, interstitial inflammatory cell infiltration mostly composed of lymphocytes. Upon inspection of H\&E slides, the UVB group showed significantly denser inflammatory cell infiltration and epidermotropism compared to the UVB + Ech A group, featured by lymphocyte exocytosis, spongiosis, and subsequent proliferation of the epidermis. Furthermore, the distribution and amount of dermal collagen fiber were diffuse and dense in the UVB + Ech A group, whereas the UVB group showed a marked decrease in collagen fiber. Toluidine blue stain showed more dense infiltration of mast cells in the UVB group than the UVB + Ech A group (Figure 5).

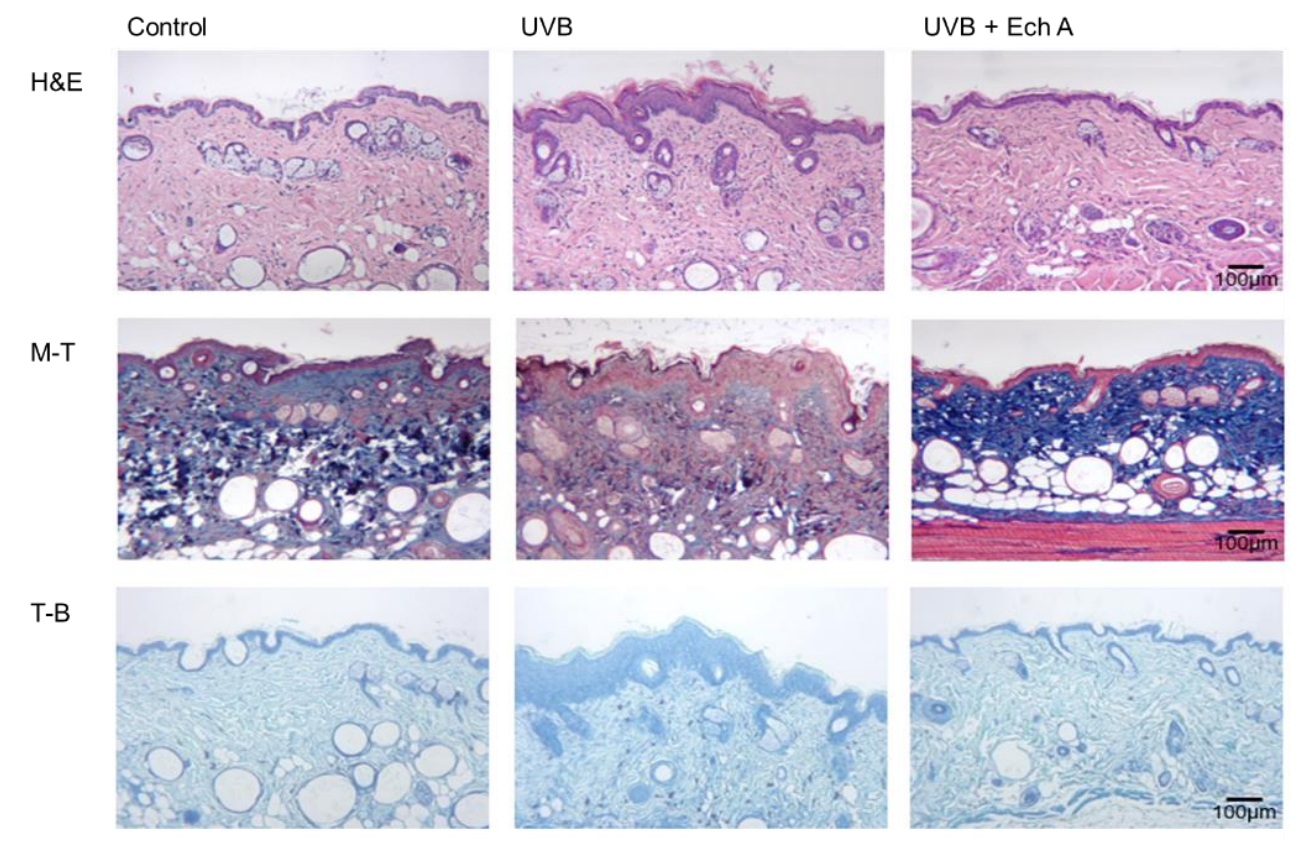

Figure 5. Histological observation of the dorsal skin of UV-irradiated mice and age-matched nontreated mice. Significant epidermal changes, such as hyperkeratosis, acanthosis, spongiosis, and papillomatosis, were observed. Dermal changes were accompanied by perivascular and interstitial inflammatory cell infiltration. Epidermal and dermal changes were more evident in the control than in the group treated with Ech A. In the Masson's trichome $(\mathrm{M}-\mathrm{T}, \times 100)$ staining, a significant decrease in dermal collagen fibers was observed in the UVB compared to the UVB + Ech A group. Furthermore, toluidine blue $(\mathrm{T}-\mathrm{B}, \times 100)$ staining showed more dense mast cell infiltration in the UVB group than the UVB + Ech A-treated group.

The number of mast cells was counted in sum of 5 high power field in each toluidineblue stained slide (Figure 6A). Mean mast cell count was significantly higher in the UVB group than in the UVB + Ech A-treated group (Figure 6B).

2.4. Effects of Ech A on the Immunohistochemical Expression Levels of Collagen 1,3, MMP 1,2,9 and Beta-Galactosidase of the Mouse Skin

Immunohistochemical staining was conducted on the dorsal skin of mice with six antibodies, including anti-collagen 1,3 antibody, anti-MMP 1,2,9 antibodies, and betagalactosidase antibody. The staining results for each molecule showed different distribution among the three groups. Higher amounts of collagen 1 and 3 were observed in the UVB + Ech A group than in the UVB group, whereas MMP 1, 2, and 9 were more densely stained in the UVB group compared to the UVB + Ech A group. However, there was no significant difference in beta-galactosidase staining among all the groups (Figure 7). 
A

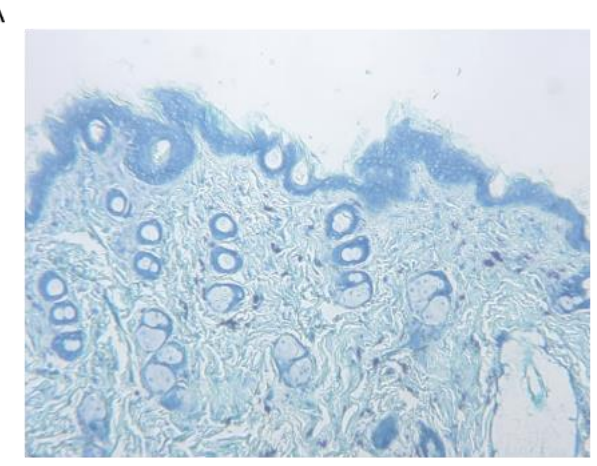

B

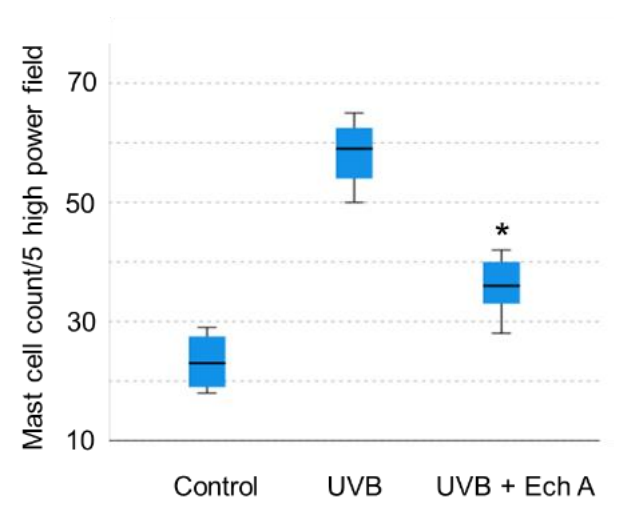

Figure 6. Histologic appearance of dorsal skin $(A$, toluidine blue, $\times 100)$ and statistical analysis of mast cell count (B). UVB irradiation induced a significant increase in the mast cell count, while the UVB group showed more dense mast cell infiltration compared to the UVB + Ech A group. ${ }^{*}, p<0.05$ vs. UVB.

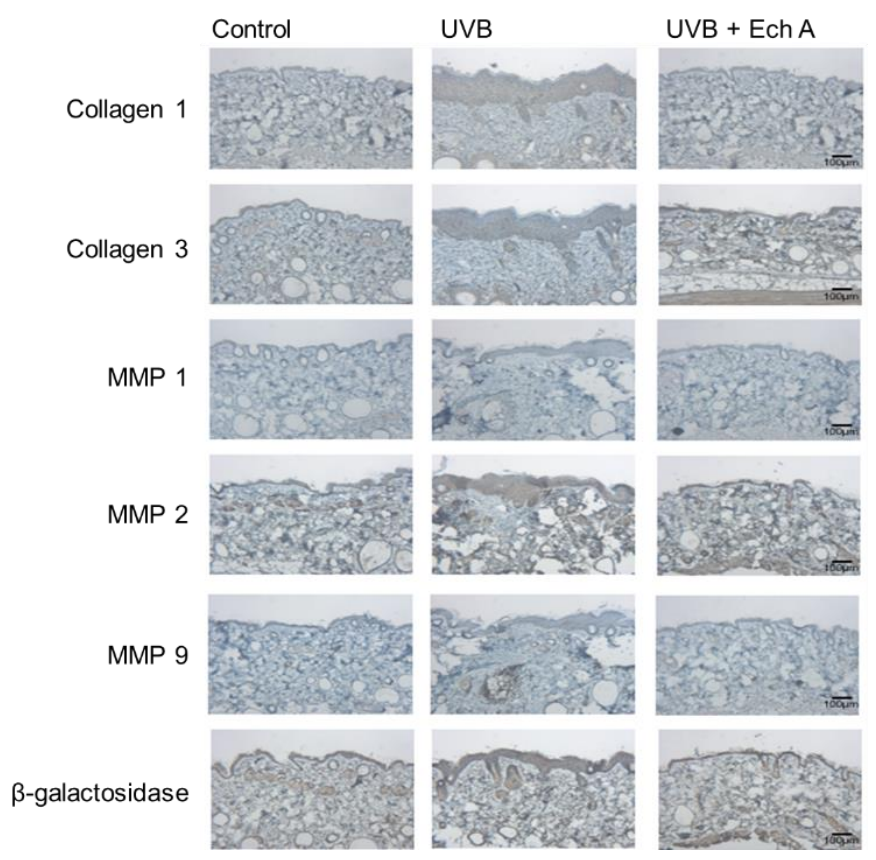

Figure 7. Immunohistochemical staining of biopsy specimen of the dorsal skin of mice. Biopsy specimens were stained with anti-collagen 1,3 antibodies, anti-MMP 1, 2, 9 antibodies, and betagalactosidase antibody. Higher amounts of collagen 1 and 3 were observed in the UVB + Ech A group than in the UVB group, while higher amounts of MMP 1, 2, and 9 were observed in the UVB than in the UVB + Ech A group. Beta-galactosidase stained all groups similarly ( $\times 100$ magnification).

\subsection{Effects of Ech A on the Expression of Matrix Metalloproteinase, Tryptase, and Chymase of the} Mouse Skin

The relative expressions of MMP 1, 2, tryptase, and chymase were significantly increased in the UVB group compared to the control and the UVB + Ech A groups (Figure 8). However, there was no significant difference in expression between the control and the UVB + Ech A groups (Figure 8). Although the expression of MMP 9 was slightly higher in the UVB group, it was too trivial to compare the expression among all groups. 


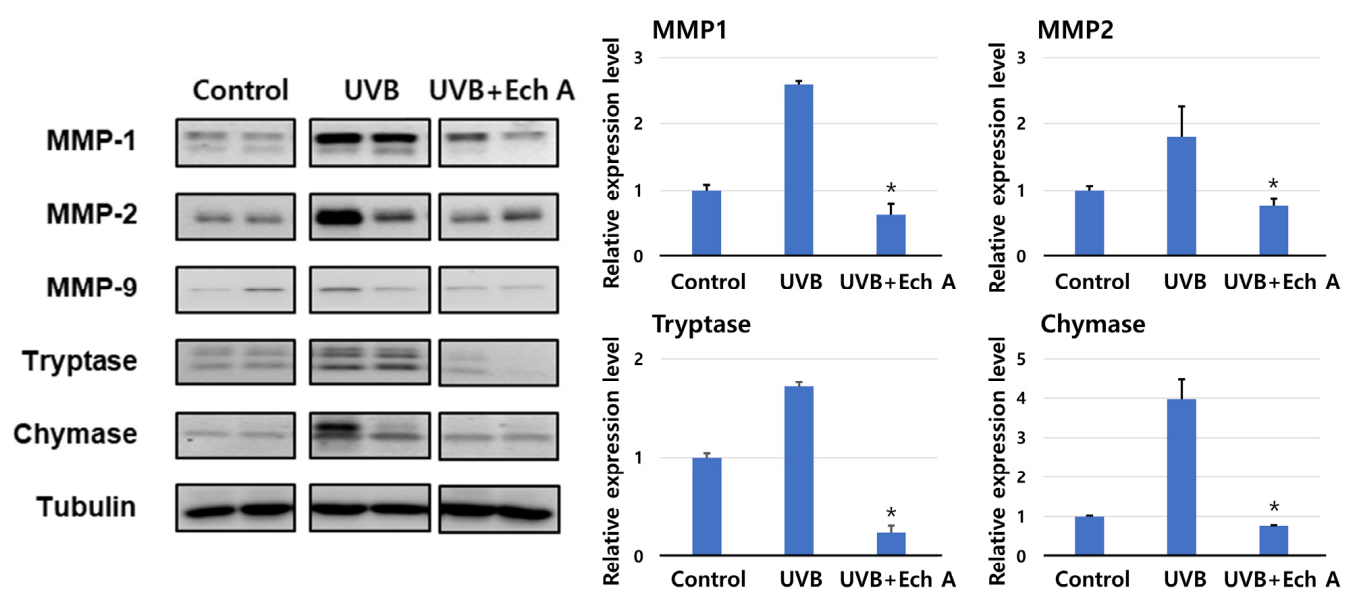

Figure 8. Western blotting of biopsy specimen of the dorsal skin of mice. Western blotting showed increased expression of MMP 1,2, tryptase, and chymase in the UVB group compared to the control and the UVB + Ech A groups. ${ }^{*} p<0.05$ vs. UVB.

\section{Discussion}

Skin undergoes two distinct types of aging. Intrinsic skin aging is caused by inevitable physiologic changes, including a weakened intrinsic antioxidant defense system, proteasome activity, and telomerase function [11]. It is characterized by dry and pale skin with fine wrinkles and increased laxity. In contrast, extrinsic skin aging, also called photoaging, includes the preventable structural and functional changes that are mostly induced by unprotected ultraviolet exposure [12]. Typical features of photoaging are deep wrinkles, laxity, coarseness, increased fragility, and multiple telangiectasia. Both types of aging share a common pathophysiology of oxidative damage, which triggers downstream events in the proinflammatory pathway, including changes in nuclear factor $\mathrm{\kappa B}$, interleukin- 1 and 6 , vascular endothelial growth factor, and tumor necrosis factor- $\alpha$. This is followed by the deterioration of intracellular proteins, the induction of matrix-degrading metalloproteins, and DNA damage, including the disruption of the normal loop structure at the end of telomeres [11-15].

In the process of photoaging, UVB is the primary source of direct DNA damage and inflammation. UVB ( 280 to $320 \mathrm{~nm}$ ) can penetrate the epidermis and upper portion of the dermis, while UVA ( 320 to $400 \mathrm{~nm}$ ) can deeply penetrate the skin down to the lower dermis. In addition to the common mechanism of aging, UV damage contributes to further collagen degradation and the production of elastotic material in the skin [30,31]. Photoaging is also associated with mitochondrial DNA mutation and decreased metabolic function through the generation of reactive oxygen species [30,31]. Furthermore, UV irradiation also induces basement membrane disruption and accumulation of matrix metalloproteinases and urinary plasminogen activator in the skin [32]. The fragmentation of collagen due to degradation is crucial step in the clinical appearance of wrinkle formation [33].

Numerous studies dealing with protection against photoaging have been carried out. The anti-inflammatory and anti-oxidative properties of various molecules, including flavonoids, polyphenols, carotenoids, and vitamins $\mathrm{C}$ and $\mathrm{E}$, and natural extracts, have been investigated with regard to their ability to prevent or stimulate collagen degeneration or synthesis [13,14,18-24]. However, no previous study exploring the therapeutic potential of marine bioactive material in skin photoaging has been carried out.

Ech A, which is a natural quinoid pigment in the polyhydroxynaphthaquinone family that is extracted from sea urchin shells or spines, has been studied regarding its antioxidative abilities through the moiety of metal chelator [2]. In previous studies, Ech A was found to activate the transcription of genes responsible for mitochondrial biogenesis in vitro and modulate mitochondrial respiration in the cardiomyoblast $\mathrm{H} 9 \mathrm{c} 2$ cell line and isolated rat cardiomyocytes [6]. Furthermore, Ech A has shown anti-inflammatory properties in studies of gastric ulcer, acute uveitis, and inflammatory bowel disease models [6-9]. 
Based on its anti-oxidative and anti-inflammatory properties and efficacy in mitochondrial functional improvement, Ech A has been speculated to have therapeutic potential against photoaging, considering its common pathophysiology characterized by oxidative stressinduced proinflammatory cytokine secretion and collagen degradation. Therefore, this study investigated the effect of Ech A on UV-induced skin photoaging in structural and functional aspects using a hairless mouse model.

As the effect of Ech A on the skin has not been studied so far, little data are available regarding the extent of the systemic absorption of Ech A through oral intake. Consequently, methods of intraperitoneal injection were adopted in this study and further research is needed to investigate the pharmacokinetics and pharmacodynamics of Ech A under variable routes of administration.

Transepidermal water loss (TEWL) and stratum corneum hydration (SCH) are widely adopted indexes used to assess skin barrier function [34,35]. In this experiment, UVB exposure was found to significantly increase TEWL and decrease SCH in both the UVB and the UVB + Ech A groups. This result indicates the clinical effect of UVB exposure on the deterioration of general skin barrier function. In particular, the extent of TEWL elevation was attenuated by Ech A treatment, implying the protective effect of Ech A on skin barrier function. Although SCH was not found to be significantly different between the UVB and the UVB + Ech A groups, it is speculated that the experimental period was too short to fully display the long-term effect of improved skin barrier function on moisture retention. A more prolonged period of study is necessary in order to evaluate the precise correlation between skin barrier function and stratum corneum hydration state in hairless mice. Similarly, an extended period of observation is necessary in order to detect changes in macroscopic appearance caused by any histologic improvement.

The histopathologic effect of UV irradiation has been well studied and the hairless mouse is known to express various epidermal and dermal changes similar to that of human skin [34]. Continuous UV irradiation can induce epidermal and dermal changes in hairless mouse skin, including hyperkeratosis, acanthosis, dermal perivascular inflammatory cell infiltration, the excessive deposition of the abnormal elastin complex, and (most importantly) the impairment of collagen fibers [34,36,37]. Collagens 1 and 3 are crucial components of tissue tensile strength, being abundantly distributed in the dermis and polymerized to extended fibrils [38]. Therefore, it is widely accepted that dermal collagen density and distribution are responsible for the wrinkle formation in photoaged skin $[33,39,40]$.

In this study, UVB irradiation caused significant histopathologic changes similar to those seen in previous studies, showing marked hyperkeratosis, proliferation of the Malpighi layer, spongiosis, papillomatosis, perivascular and interstitial inflammatory cell infiltration, increased levels of mast cells, and decreased levels of collagen fibers. Ech A intraperitoneal injection attenuated all the histopathologic changes, showing less severe epidermal changes along with more compact collagen fiber distribution and a lower mast cell count. These protective effects of Ech A are speculated to be achieved by the anti-oxidative and anti-inflammatory mechanism through modulating mitochondrial metabolism, as in other studies involving cardiomyocytes, gastric mucosal cells, or eye corneal cells [6-9].

Matrix metalloproteinases (MMPs) are zinc-binding proteolytic enzymes that mediate extracellular matrix degradation and tissue remodeling [41]. Various types of MMPs including MMP 1, 2, 3, and 9 share a common molecular structure and degrade specific ECM substrates [42]. Based on this property, MMPs are widely used as useful markers for severe photoaging. In particular, MMP2 and 9 are the main gelatinases increased by UV irradiation in a hairless mouse model, degrading the dermal collagen and basement membrane $[43,44]$. In addition, MMP 1 acts as a crucial proteinase in human skin photoaging and has also been suggested to be a molecule regulating interleukin- $1 \alpha$ and $\beta$ induced by UV irradiation in a mouse model [45]. Ech A was found to reduce the amount of MMPs in both immunohistochemistry and Western blotting, indicating that the clinical efficacy 
of Ech A originates from the reduced collagen degradation and dermal inflammatory cell recruitment, including mast cells, rather than from stimulating collagen synthesis.

Beta galactosidase is another indicator of photoaging [46]; however, no significant change was found after the application of Ech A. It is possible that Ech A may not target the beta galactosidase-associated pathway, or that the expression of beta galactosidase could be low in hairless mice. The use of a longer schedule of experiments might induce significant differences in beta galactosidase.

\section{Materials and Methods}

\subsection{Preparation of Ech $A$}

Histochrome ${ }^{\circledR}$ containing 1\% Ech A (PN002363/02) was obtained from the Pacific Institute of Bioorganic Chemistry, Far East Branch of the Russian Academy of Sciences. The composition of Histichrome is 1\% of Ech A in sodium carbonate and sodium chloride $0.9 \%$ isotonic solution and the concentration is $37.5 \mathrm{mM}$. It was kept in refrigerator at $2{ }^{\circ} \mathrm{C}$.

\subsection{Care and Use of Animals}

This study was conducted with the approval of scientific and ethical standards given by Inje University Institutional Animal Care and Use Committee (IU-IACUC; approval number 2020-002). The animals used in the experiment were six-week-old SKH-1 hairless mice purchased from Orient Bio Laboratory Animals (Dae jeon, Korea). All mice were raised in $12 \mathrm{~h}$ light/dark cycles at a temperature of $22 \pm 2{ }^{\circ} \mathrm{C}$ and $45 \pm 5 \%$ humidity and given free access to a standard irradiated chow diet and water.

\subsection{Experimental Design}

All mice $(n=20)$ were assigned to one of three groups: a not-treated group (not treated; control, $\mathrm{n}=4$ ) and two UV radiation groups. The UV radiation groups were subdivided into a phosphate-buffered saline (PBS) intraperitoneal injection group (UVB, $n=8)$ and an Ech A intraperitoneal injection group (UVB + Ech A, $n=8)$.

\subsection{UV Irradiation}

A UV irradiation device was manufactured by NSC, Inc. (Hwasung, Korea) in the shape of a rectangular box that was $60 \mathrm{~cm}$ wide, $40 \mathrm{~cm}$ long, and $40 \mathrm{~cm}$ high. The device was equipped with a TL20W/01RS lamp (Phillips ${ }^{\mathrm{TM}}$, Eindhoven, Netherlands) that emitted UVB with a narrow peak wavelength of $311 \mathrm{~nm}$. The distance between the UV lamp and the mouse was maintained at $30 \mathrm{~cm}$, and the amount of UVB emitted was measured by an ILT-1700 Research Radiometer (International Light Technology ${ }^{\mathrm{TM}}$, Boston, MA, USA). The eight-week schedule of irradiation included irradiation every two days, with the mice resting for two days after every third radiation given each week. The UVB was given at the amount of 1 minimal erythema dose (1 MED) during the first week, gradually rising to 2 MED, 3 MED, and 4 MED during the next 3 weeks, and then reaching a plateau at 4 MED until the end of the 8th week.

\subsection{Setting $1 M E D$}

MED refers to the minimum UV irradiation amount that can cause erythema on the skin. MED is generally used as a practical indicator for determining the degree of effects of UV irradiation. In order to set the level of $1 \mathrm{MED}$, a cloth with a hole $1 \mathrm{~cm}$ in diameter was used to cover the dorsal skin of the mouse, and six different areas were irradiated with 60 , $80,100,120,140$, and $160 \mathrm{~mJ}$. The amount of UVB at the height of mouse was calculated as about $1 \mathrm{~mJ}$ per second, so setting MED took about $11 \mathrm{~min}$ of irradiation. After $24 \mathrm{~h}$, it was observed whether erythema had occurred in any of the six points. 


\subsection{Intraperitoneal Injection}

Immediately after UVB irradiation, the UVB and UVB + Ech A groups were injected with the reagents in the intraperitoneal space. UVB group was administrated with PBS $200 \mu \mathrm{L}$. Ech A dose in UVB + Ech A group was $0.1 \mathrm{mg} / \mathrm{kg}$ of Ech A mixed with PBS $200 \mu \mathrm{L}$.

\subsection{Clinical Observation of skin Condition}

In order to check the change in the dorsal skin conditions, photographs were taken with a camera and dermoscope (DermLite ${ }^{\mathrm{TM}}$ DLCAM, Dermlite, San Juan Capistrano, CA, USA) before every first irradiation day of each week. Mice were photographed under anesthesia, which was administered through inhaling isoflurane briefly.

\subsection{Measurement of Transepidermal Water Loss, Stratum Corneum Hydration}

The day after the completion of every 2 week schedule of UV irradiation, the transepidermal water loss (TEWL) and stratum corneum hydration $(\mathrm{SCH})$ were measured by a tewameter and corneometer using a Cutometer ${ }^{\mathrm{TM}}$ MPA 580 (Courage and Khazaka Electronics ${ }^{\mathrm{TM}}$, Cologne, Germany). A measuring probe was placed on the middle portion of the dorsal skin of the mice, which were anesthetized by inhaling a low concentration of isoflurane. Values of TEWL were read at the plateau of the estimation graph, while SCH values were taken as the mean value of three measurements.

\subsection{Histological Analysis}

Two days after the last UV irradiation, all mice were sacrificed using $\mathrm{CO}_{2}$ gas to collect the dorsal skin tissue samples. Collected samples were cut into four pieces and one of them was fixed with $4 \%$ paraformaldehyde solution at room temperature for $24 \mathrm{~h}$, then transported in 50\% ethyl alcohol solution. After another $24 \mathrm{~h}$, the samples were embedded in paraffin wax and sectioned into $4 \mu \mathrm{m}$ slices. The skin sections were stained with hematoxylin and eosin (H\&E), Masson's trichrome, and toluidine blue. Immunohistochemistry staining was conducted with anti-collagen I antibody, anti-MMP9 antibody, and anti-beta galactosidase antibody purchased from Abcam ${ }^{\circledR}$ (Cambridge, UK), as well as anti-collagen III polyclonal antibody, anti-MMP 1 polyclonal antibody, and anti-MMP2 monoclonal antibody purchased from Invitrogen ${ }^{\mathrm{TM}}$ (Carlsbad, CA, USA). Stained slides were observed and photographed by optical microscopy Olympus ${ }^{\mathrm{TM}} \mathrm{BH} 2$ (Tokyo, Japan) and a Tucsen ${ }^{\mathrm{TM}}$ Digiretina 16 (Fuzhou, China). Epidermal thickness was measured in H\&E-stained slides through the computer-assisted program Tucsen ${ }^{\text {TM }}$ TCapture (Fuzhou, China). The mean epidermal thickness was calculated by measuring the distance between the dermoepidermal junction and the top of stratum granulosum at five different areas in each specimen at a magnification of $\times 200$. In addition, papillomatosis width was measured as the horizontal distance between the shoulders of the papillomatosis, while depth was calculated as the shortest distance between the bottom point of the basal layer sulcus and the horizontal line between papillomatosis shoulders. In addition, the number of mast cells on a toluidine blue-stained slide was calculated as the mean value of 5 randomly chosen visual fields at $\times 100$ magnification.

\subsection{Western Blot}

Mouse dorsal skin tissues were lysed with radioimmunoprecipitation assay (RIPA) buffer ( $50 \mathrm{mM}$ Tris- $\mathrm{HCl}, \mathrm{pH} 7.5,150 \mathrm{mM} \mathrm{NaCl}, 0.5 \%$ sodium deoxycholate, $1 \%$ Triton $\mathrm{X}-100,2 \mathrm{mM}$ EDTA, and $0.1 \%$ SDS) supplemented with protease and phosphatase inhibitors (200 mM PMSF). The protein concentration was analyzed using a Bio-Rad DC protein assay (Bio-Rad Laboratories, Inc., Hercules, CA, USA). The lysate was separated by $8 \sim 15 \%$ sodium dodecyl sulfate polyacrylamide gel electrophoresis (SDS-PAGE) and transferred onto a nitrocellulose membrane (GE Healthcare, Chicago, IL, USA) for $100 \mathrm{~min}$ at $100 \mathrm{~V}$ at $4{ }^{\circ} \mathrm{C}$. Membranes were blocked with $5 \%$ skim milk in TBST $(20 \mathrm{mmol} / \mathrm{L}$ Tris$\mathrm{HCl}$, pH 7.5, $50 \mathrm{mmol} / \mathrm{L} \mathrm{NaCl}$, and $0.1 \%$ Tween 20). After blocking, the membranes were incubated for overnight with primary antibodies diluted to 1:1000 in 3\% bovine serum 
albumin (BSA) in TBST. After washing 3 times for $15 \mathrm{~min}$, the membranes were incubated for $1 \mathrm{~h}$ with horseradish peroxidase-labeled secondary antibody diluted to 1:5000 in 3\% BSA. The protein bands were visualized using an enhanced chemiluminescence kit (Santa Cruz Biotechnology, Dallas, TX, United States), then observed with an AI 600 Imager (GE Healthcare, Chicago, IL, USA).

\subsection{Statistical Analysis}

Using the SPSS program (version 10.0; SPSS Inc., Chicago, IL, USA), continuous variables were presented as averages with standard errors. Correlation analysis, $t$-test, and repeated measures ANOVA methods were used to determine the association between each factor, and regression or logistic regression were used. A $p$-value of $<0.05$ was considered statistically significant.

\section{Conclusions}

In this study, Ech A showed a protective effect against UVB-induced photoaging in both functional and structural aspects. It is estimated to be induced by the anti-oxidative and anti-inflammatory properties of Ech A, affecting the mitochondrial metabolism. Inhibitory effects on mast cells and MMP might contribute to histologic differences, such as attenuated epidermal thickening, lower levels of inflammatory cell infiltration, and preserved collagen fiber, followed by the ultimate improvement of the skin barrier function.

To the best of our knowledge, this is the first study dealing with the effect of Ech A on skin photoaging in a murine model. It is possible that there are other contributory signal pathways or cytokines such as transcription factor activation protein 1 or nuclear factor kappa B. To compensate for the limitations of this study, it is necessary to determine the precise molecular mechanism or signal cascade pathways on variable target cells through further research.

Author Contributions: Conceptualization; J.E.S. and J.H.; methodology and data analysis, S.W.A., B.S., H.R.Y., N.P.; providing material and supporting experiments, E.A.V., N.P.M., S.A.F. and V.A.S.; writing—original draft preparation, J.E.S. and J.H.; writing—review and editing, J.E.S., H.K.K., and J.H. All authors have read and agreed to the published version of the manuscript.

Funding: This work was supported by the 2019 Inje University research grant.

Institutional Review Board Statement: This study was conducted with the approval of the scientific and ethical standards from Inje University Institutional Animal Care and Use Committee (IU-IACUC; approval number 2020-002).

Data Availability Statement: This article does not data and the data availability policy is not applicable to the article.

Conflicts of Interest: The authors declare no conflict of interest.

\section{References}

1. Shikov, A.N.; Pozharitskaya, O.; Krishtopina, A.S.; Makarov, V.G. Naphthoquinone pigments from sea urchins: Chemistry and pharmacology. Phytochem. Rev. 2018, 17, 509-534. [CrossRef]

2. Lebedev, A.V.; Ivanova, M.V.; Levitsky, D.O. Echinochrome, a naturally occurring iron chelator and free radical scavenger in artificial and natural membrane systems. Life Sci. 2005, 76, 863-875. [CrossRef]

3. Bummov, G.A.; Maksimov, I.V.; Perchatkin, V.A.; Repin, A.N.; Afanas'ev, S.A.; Markov, V.A.; Karpov, R.S. Vliianie bioantioksidanta gistrokhroma na povrezhdenie miokarda pri reperfuzionno terapii u bol'nykh infarktom miokardom [Effect of the bioan-tioxidant histochrome on myocardial injury in reperfusion therapy on patients with myocardial infarction]. Ter Arkh. 2002, 74, 12-16.

4. Egorov, E.A.; Alekhina, V.A.; Volobueva, T.M.; Fedoreev, S.A.; Mishchenko, N.P.; Kol'tsova, E.A. Novyĭ bioantioksidant "Gistokhrom" v klinike glaznykh bolezneĭ [Histochrome, a new antioxidant, in the treatment of ocular diseases]. Vestn. -talmol. 1999, 115, 34-35.

5. Prokopov, I.A.; Kovaleva, E.L.; Minaeva, E.D.; Pryakhina, E.A.; Savin, E.V.; Gamayunova, A.V.; Pozharitskaya, O.N.; Makarov, V.G.; Shikov, A.N. Animal-derived medicinal prod-ucts in Russia: Current nomenclature and specific aspects of quality control. J. Ethnopharmacol. 2019, 240, 111933. [CrossRef] 
6. Jeong, S.H.; Kim, H.K.; Song, I.S.; Lee, S.J.; Ko, K.S.; Rhee, B.D.; Kim, N.; Mishchenko, N.P.; Fedoryev, S.A.; Stonik, V.A.; et al. Echino-chrome A protects mitochondrial function in cardiomyocytes against cardiotoxic drugs. Mar. Drugs. 2014, 12, $2922-2936$. [CrossRef] [PubMed]

7. Sayed, D.A.; Soliman, A.M.; Fahmy, S.R. Echinochrome pigment as novel therapeutic agent against experimentally-Induced gastric ulcer in rats. Biomed. Pharmacother. 2018, 107, 90-95. [CrossRef]

8. Lennikov, A.; Kitaichi, N.; Noda, K.; Mizuuchi, K.; Ando, R.; Dong, Z.; Fukuhara, J.; Kinoshita, S.; Namba, K.; Ohno, S.; et al. Ame-lioration of endotoxin-induced uveitis treated with the sea urchin pigment echinochrome in rats. Mol. Vis. 2014, 20, 171-177.

9. Oh, S.-J.; Seo, Y.; Ahn, J.-S.; Shin, Y.Y.; Yang, J.W.; Kim, H.K.; Han, J.; Mishchenko, N.P.; Fedoreyev, S.A.; Stonik, V.A.; et al. Echinochrome A Reduces Colitis in Mice and Induces In Vitro Generation of Regulatory Immune Cells. Mar. Drugs 2019, 17, 622. [CrossRef]

10. Kim, H.; Vasileva, E.; Mishchenko, N.; Fedoreyev, S.; Han, J. Multifaceted Clinical Effects of Echinochrome. Mar. Drugs 2021, 19, 412. [CrossRef]

11. Rittié, L.; Fisher, G.J. UV-light-induced signal cascades and skin aging. Ageing. Res. Rev. 2002, 1, 705-720. [CrossRef]

12. Fisher, G.J.; Wang, Z.Q.; Datta, S.C.; Varani, J.; Kang, S.; Voorhees, J.J. Pathophysiology of premature skin aging induced by ultravi-olet light. N Engl. J. Med. 1997, 337, 1419-1428. [CrossRef]

13. Masaki, H. Role of antioxidants in the skin: Anti-aging effects. J. Dermatol. Sci. 2010, 58, 85-90. [CrossRef]

14. Yasin, Z.A.M.; Ibrahim, F.; Rashid, N.N.; Razif, M.F.M.; Yusof, R. The Importance of Some Plant Extracts as Skin Anti-aging Re-sources: A Review. Curr. Pharm. Biotechnol. 2017, 18, 864-876. [CrossRef] [PubMed]

15. Lavker, R.M.; Gerberick, G.; Veres, D.; Irwin, C.J.; Kaidbey, K.H. Cumulative effects from repeated exposures to suberythemal doses of UVB and UVA in human skin. J. Am. Acad. Dermatol. 1995, 32, 53-62. [CrossRef]

16. Petruk, G.; Del Giudice, R.; Rigano, M.M.; Monti, D.M. Antioxidants from Plants Protect against Skin Photoaging. Oxidative Med. Cell. Longev. 2018, 2018, 1-11. [CrossRef] [PubMed]

17. Sotiropoulou, G.; Zingkou, E.; Pampalakis, G. Redirecting drug repositioning to discover innovative cosmeceuticals. Exp. Dermatol. 2021, 30, 628-644. [CrossRef] [PubMed]

18. Kim, S.-Y.; Kim, S.-J.; Lee, J.-Y.; Kim, W.-G.; Park, W.-S.; Sim, Y.-C.; Lee, S.-J. Protective effects of dietary soy isoflavones against UV-induced skin-aging in hairless mouse model. J. Am. Coll. Nutr. 2004, 23, 157-162. [CrossRef] [PubMed]

19. Hwang, I.S.; Kim, J.E.; Choi, S.I.; Lee, H.R.; Lee, Y.J.; Jang, M.J.; Son, H.J.; Lee, H.S.; Oh, C.H.; Kim, B.H.; et al. UV radia-tioninduced skin aging in hairless mice is effectively prevented by oral intake of sea buckthorn (Hippophae rhamnoides L.) fruit blend for 6 weeks through MMP suppression and increase of SOD activity. Int. J. Mol. Med. 2012, 30, 392-400. [CrossRef]

20. Davinelli, S.; Bertoglio, J.C.; Polimeni, A.; Scapagnini, G. Cytoprotective Polyphenols Against Chronological Skin Aging and Cutaneous Photodamage. Curr. Pharm. Des. 2018, 24, 99-105. [CrossRef] [PubMed]

21. Huh, M.K.; Han, M.D. Inhibitory effect of Hyaluronidase and DPPH radical scavenging activity using extraction of Equisetum arvens. Europ. J. Adv. Res. Biologic. Life Sci. 2015, 3, 47-51.

22. Song, E.; Chung, H.; Shim, E.; Jeong, J.K.; Han, B.K.; Choi, H.J.; Hwang, J. Gastrodia elata Blume Extract Modulates Antioxidant Ac-tivity and Ultraviolet A-Irradiated Skin Aging in Human Dermal Fibroblast Cells. J. Med. Food. 2016, 19, 1057-1064. [CrossRef] [PubMed]

23. Park, G.; Sim, Y.; Lee, W.; Sung, S.H.; Oh, M.S. Protection on Skin Aging Mediated by Antiapoptosis Effects of the Water Lily (Nymphaea Tetragona Georgi) via Reactive Oxygen Species Scavenging in Human Epidermal Keratinocytes. Pharmacology 2016, 97, 282-293. [CrossRef] [PubMed]

24. Garbossa, W.A.C.; Campos, P.M.B.G.M. Euterpe oleracea, Matricaria chamomilla, and Camellia sinensis as promising ingredi-ents for development of skin care formulations. Ind. Crops. Prod. 2016, 83, 1-10. [CrossRef]

25. Fernando, I.; Heo, S.-J.; Dias, M.; Madusanka, D.; Han, E.-J.; Kim, M.-J.; Sanjeewa, K.; Lee, K.; Ahn, G. (-)-Loliolide Isolated from Sargassum horneri Abate UVB-Induced Oxidative Damage in Human Dermal Fibroblasts and Subside ECM Degradation. Mar. Drugs 2021, 19, 435. [CrossRef]

26. Ahn, J.H.; Kim, D.W.; Park, C.W.; Kim, B.; Sim, H.; Kim, H.S.; Lee, T.K.; Lee, J.C.; Yang, G.E.; Her, Y. Laminarin Attenuates Ultraviolet-Induced Skin Damage by Re-ducing Superoxide Anion Levels and Increasing Endogenous Antioxidants in the Dorsal Skin of Mice. Mar. Drugs 2020, 18, 345. [CrossRef]

27. Kim, Y.-I.; Oh, W.-S.; Song, P.H.; Yun, S.; Kwon, Y.-S.; Lee, Y.J.; Ku, S.-K.; Song, C.-H.; Oh, T.-H. Anti-Photoaging Effects of Low Molecular-Weight Fucoidan on Ultraviolet B-Irradiated Mice. Mar. Drugs 2018, 16, 286. [CrossRef]

28. Piao, M.J.; Kang, K.A.; Ryu, Y.S.; Shilnikova, K.; Park, J.E.; Hyun, Y.J.; Zhen, A.X.; Kang, H.K.; Koh, Y.S.; Ahn, M.J.; et al. The Red Algae Compound 3-Bromo-4,5-dihydroxybenzaldehyde Protects Human Keratinocytes on Oxidative Stress-Related Molecules and Pathways Activated by UVB Irradiation. Mar. Drugs 2017, 15, 268. [CrossRef]

29. Sanjeewa, K.K.A.; Kim, E.-A.; Son, K.-T.; Jeon, Y.-J. Bioactive properties and potentials cosmeceutical applications of phlorotannins isolated from brown seaweeds: A review. J. Photochem. Photobiol. B Biol. 2016, 162, 100-105. [CrossRef]

30. Krutmann, J.; Liu, W.; Li, L.; Pan, X.; Crawford, M.; Sore, G.; Seite, S. Pollution and skin: From epidemiological and mechanistic studies to clinical implications. J. Dermatol. Sci. 2014, 76, 163-168. [CrossRef]

31. Fernandez, T.L.; Van Lonkhuyzen, D.R.; Dawson, R.A.; Kimlin, M.; Upton, Z. Characterization of a Human Skin Equivalent Model to Study the Effects of Ultraviolet B Radiation on Keratinocytes. Tissue Eng. Part C Methods 2014, 20, 588-598. [CrossRef] 
32. Amano, S. Possible Involvement of Basement Membrane Damage in Skin Photoaging. J. Investig. Dermatol. Symp. Proc. 2009, 14, 2-7. [CrossRef]

33. Takema, Y.; Hattori, M.; Aizawa, K. The relationship between quantitative changes in collagen and formation of wrinkles on hairless mouse skin after chronic UV irradiation. J. Dermatol. Sci. 1996, 12, 56-63. [CrossRef]

34. Bissett, D.; Hannonand, D.; Orr, T. An animal model of solar-aged skin: Histological, physical, and visible changes in uv-irradiated hairless mouse skin. Photochem. Photobiol. 1987, 46, 367-378. [CrossRef]

35. Alexander, H.; Brown, S.; Danby, S.; Flohr, C. Research Techniques Made Simple: Transepidermal Water Loss Measurement as a Research Tool. J. Investig. Dermatol. 2018, 138, 2295-2300.e1. [CrossRef] [PubMed]

36. Park, C.-H.; Lee, M.J.; Kim, J.-P.; Yoo, I.D.; Chung, J.H. Prevention of UV Radiation-Induced Premature Skin Aging in Hairless Mice by the Novel Compound Melanocin A. Photochem. Photobiol. 2006, 82, 574-578. [CrossRef] [PubMed]

37. Moloney, S.J.; Edmonds, S.H.; Giddens, L.D.; Learn, D.B. The hairless mouse model of photoaging: Evaluation of the relationship between dermal elastin, collagen, skin thickness and wrinkles. Photochem. Photobiol. 1992, 56, 505-511. [CrossRef] [PubMed]

38. Gosline, J.; Lillie, M.; Carrington, E.; Guerette, P.; Ortlepp, C.; Savage, K. Elastic proteins: Biological roles and mechanical proper-ties. Philos. Trans. R Soc. Lond. B Biol. Sci. 2002, 357, 121-132. [CrossRef] [PubMed]

39. Miyachi, Y. Photoaging from an oxidative standpoint. J. Dermatol. Sci. 1995, 9, 79-86. [CrossRef]

40. Yan, S.X.; Hong, X.Y.; Hu, Y.; Liao, K.H. Tempol, one of nitroxides, is a novel ultraviolet-A1 radiation protector for human der-mal fibroblasts. J. Dermatol. Sci. 2005, 37, 137-143. [CrossRef]

41. Fini, M.E.; Girard, M.T.; Matsubara, M. Collagenolytic/gelatinolytic enzymes in corneal wound healing. Acta Ophthalmol. Suppl. 1992, 70, 26-33. [CrossRef] [PubMed]

42. Azar, D.T.; Hahn, T.W.; Jain, S.; Yeh, Y.C.; Stetler-Stevensen, W.G. Matrix metalloproteinases are expressed during wound healing after excimer laser keratectomy. Cornea 1996, 15, 18-24. [CrossRef]

43. Fortino, V.; Maioli, E.; Torricelli, C.; Davis, P.; Valacchi, G. Cutaneous MMPs are differently modulated by environmental stressors in old and young mice. Toxicol. Lett. 2007, 173, 73-79. [CrossRef] [PubMed]

44. Brenneisen, P.; Wenk, J.; Wlaschek, M.; Krieg, T.; Scharffetter-Kochanek, K. Activation of p70 ribosomal protein S6 kinase is an essential step in the DNA damage-dependent signaling pathway responsible for the ultraviolet B-mediated increase in in-terstitial collagenase (MMP-1) and stromelysin-1 (MMP-3) protein levels in human dermal fibroblasts. J. Biol. Chem. 2000, 275, 4336-4344.

45. Visse, R.; Nagase, H. Matrix metalloproteinases and tissue inhibitors of metalloproteinases: Structure, function, and bio-chemistry. Circ. Res. 2003, 92, 827-839. [CrossRef] [PubMed]

46. Yang, N.C.; Hu, M.L. The limitations and validities of senescence associated-beta-galactosidase activity as an aging marker for human foreskin fibroblast Hs68 cells. Exp Gerontol. 2005, 40, 813-819. [CrossRef] 